Int. J. Dev. Biol. 52: 1015-1022 (2008)

doi: $10.1387 / \mathrm{ijdb} .082640 \mathrm{eg}$

\title{
Mouse induced pluripotent stem cells
}

\author{
EAMON GEOGHEGAN and LUCY BYRNES* \\ National University of Ireland (NUI), Galway, Ireland
}

\begin{abstract}
The recent discovery that it is possible to directly reprogramme somatic cells to an embryonic stem (ES) cell-like pluripotent state, by retroviral transduction of just four genes (Oct3) 4, Sox2, c-Myc and KIf4), represents a major breakthrough in stem cell research. The reprogrammed cells, known as induced pluripotent stem (iPS) cells, possess many of the properties of ES cells, and represent one of the most promising sources of patient-specific cells for use in regenerative medicine. While the ultimate goal is the use of iPS cells in the treatment of human disease, much of the research to date has been carried out with murine cells, and improved mouse iPS cells have been shown to contribute to live chimeric mice that are germ-line competent. Very recently, it has been reported that iPS cells can be generated by three factors without c-Myc, and these cells give rise to chimeric mice with a reduced risk of tumour development.
\end{abstract}

KEY WORDS: mouse, stem cell, induced, pluripotent, reprogrammed

\section{Introduction}

In 2006, Yamanaka and co-workers surprised the scientific community when they reported that both mouse embryonic fibroblasts and tail tip fibroblasts could be reprogrammed to a pluripotent state similar to that observed in embryonic stem (ES) cells, by retroviral transduction of just four genes (Takahashi and Yamanaka, 2006). The discovery of these 'induced pluripotent stem (iPS) cells' was generally regarded as a major development in stem cell research and gave new insights into the pathways involved in the maintenance of pluripotency. Due to the complexity of genetic and epigenetic changes involved in cell differentiation (Surani et al., 2007), it had been doubted if it would ever be possible to reprogramme somatic cells to pluripotency. With the first successful cloning experiments in mammals, it was verified that such reprogramming was, indeed possible (Wilmut et al., 1997). However, the landmark discovery by Takahashi and Yamanaka less than a decade later signalled a development, which few expected so soon.

By definition, pluripotency is the ability of a cell to give rise to all cell types of an adult organism, without the self-organising capability to form the whole organism (Niwa, 2007). In vivo, pluripotency is observed in early embryos while in vitro, pluripotency may be maintained in ES cells. ES cells may be harvested from the inner cell mass (ICM) of blastocyst stage embryos. These cells, which were first isolated from mouse embryos, can proliferate indefinitely and possess the potential to develop in an unrestricted manner (Evans and Kaufman, 1981; Martin, 1981).
In culture, the pluripotency of mouse ES cells must be maintained by addition of factors such as leukaemia inhibitory factor (LIF), which promote proliferation while preventing differentiation. Human ES cells lines have also been generated (Thomson et al., 1998), and their potential as donor sources of specialised cells in cell transplantation therapies has been widely acknowledged (Yamanaka, 2007). However, some major concerns remain for ES cell transplantation. Tissue rejection due to the patients' immune response represents a real limitation of the use of ES cells for transplantation. Another concern is that in the process of isolating ES cells, human embryos are inevitably destroyed (Yamanaka, 2007). This has been a source of constant controversy since the development of the first human ES cell lines, and it has become an important ethical and political issue. These problems may, however, be overcome by reprogramming differentiated cells to an ES cell-like, pluripotent state. Such cells could be customised for individual patients and used in the treatment of disease.

In the last decade, a number of methods have been found to induce pluripotency artificially in somatic cells, including somatic

\footnotetext{
Abbreviations used in this paper: diMeH3K9, dimethylation of histone 3 lysine 9; ES, embryonic stem; Gcnf, germ cell nuclear factor; GFP, green fluorescent protein; ICM, inner cell mass; iPS, induced pluripotent stem; LIF, leukaemia inhibitory factor; Lrh1, liver receptor homologue 1; MEFs, mouse embryonic fibroblasts; Puror ${ }^{\mathrm{r}}$, puromycin resistance gene; SCNT, somatic cell nuclear transfer; SSEA1, stage-specific embryonic antigen 1; Sox2, SRY-type high mobility group box 2; TTFs, tail tip fibroblasts.
}

\footnotetext{
*Address correspondence to: Lucy Byrnes. Department of Biochemistry, National University of Ireland, Galway, Ireland. Fax: +353-91-525-700. e-mail: lucy.byrnes@nuigalway.ie Website: http://www.nuigalway.ie/biochemistry/staff/byrnes/index.html
} 
cell nuclear transfer (SCNT) and cell fusion (Tada et al., 2001; Cowan etal., 2005; Hochedlinger and Jaenisch, 2006; Yang etal., 2007; Egli etal., 2007). Much of the research in this area has been carried out with mice, but the ultimate goal of stem-cell scientists remains the production of patient-specific pluripotent cells and their use in treatment of disease. Because both SCNT and cell fusion have posed technical and ethical problems as methods of reprogramming somatic cells, Takahashi and Yamanaka's method of reprogramming by defined factors has been hailed as the 'holy grail' of stem cell research. This method circumvents many of the problems associated with both SCNT and cell fusion and is regarded as the method with the best potential for producing patient-specific pluripotent stem cells for use in regenerative medicine. Consequently, this review will focus on this most recent method and what is known of the molecular mechanisms therein.

\section{Production of induced pluripotent stem (iPS) cells}

Since somatic cells can be reprogrammed by fusion with ES cells, it was reasoned by Takahashi and Yamanaka in their landmark experiment that ES cells contain factors that induce pluripotency, and these factors were also likely to be involved in the maintenance of pluripotency in ES cells. Based on this hypothesis, 24 different factors were selected, each of which were deemed to have a potential role in the induction of pluripotency (Takahashi and Yamanaka, 2006). These 24 factors were subdivided into three groups. The first group included transcription factors specifically expressed in ES cells such as Nanog, Oct-3/ 4, Sox2, UTF1, Sall4, Sox15 and Rex1. The second group included tumour and growth-related gene products which play key roles in ES cells such as c-Myc, Stat3, $\beta$-catenin, Grb2, Klf4, Eras and TCL1. The final group consisted of factors that are expressed specifically in ES cells, but whose functions have yet to be fully characterised. These include ESG1, ECAT1, Fbx15, ECAT8, DNMT3L, GDF3, ECAT15-1, Fthl17 and Stella. To determine which, if any of these factors induced pluripotency, an assay system was developed whereby induced expression of a pluripotency marker gene could be detected. The gene used was Fbx15,

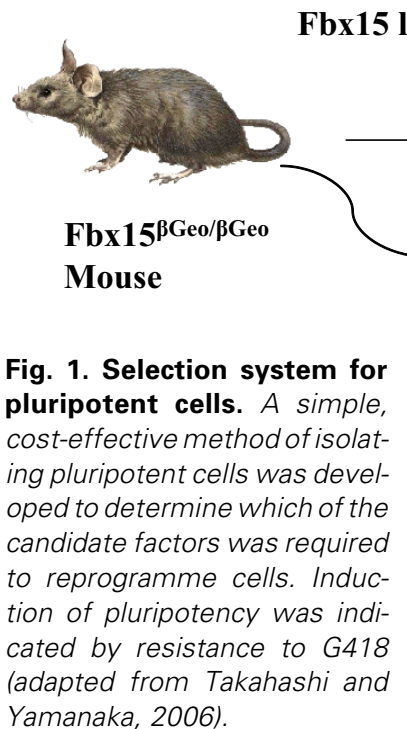

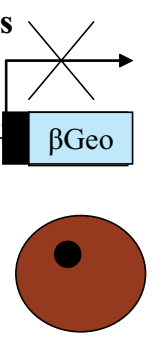

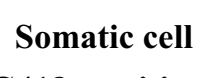

G418 sensitive

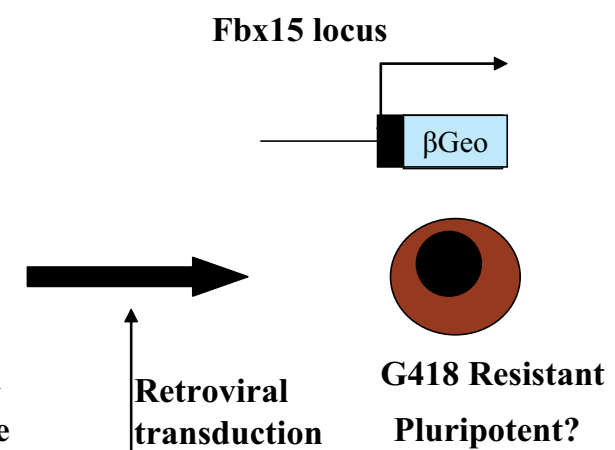

which is specifically expressed in ES cells, but is not required for development or for self-renewal of ES cells (Tokuzawa et al., 2003). Using homologous recombination, a $\beta$ geo cassette (a fusion of the $\beta$-galactosidase and neomycin resistance genes) was placed under the control of the Fbx 15 promoter. Thus, upon the induction of pluripotency, the $F b \times 15$ promoter would drive transcription of the neomycin resistance gene (Fig. 1). It was expected that even a partial induction of pluripotency would result in somatic cells becoming resistant to G418 (Takahashi and Yamanaka, 2006). Each of the genes for the 24 candidate factors were introduced into $\mathrm{Fbx} 15^{\beta \mathrm{geo} / \beta \mathrm{geo}}$ mouse embryonic fibroblasts (MEFs) by retrovirus-mediated transfection and these cells were subsequently cultured on ES cell medium containing G418. While no drug-resistant colonies were observed following introduction of any single factor, a number of colonies resistant to G418 were observed following introduction of all 24 factors. Some of these clones had morphology and doubling times similar to ES cells and exhibited ES cell markers, as determined by RT-PCR. This suggested that a particular combination of some of the 24 factors caused the ES cell marker genes to be re-activated. These cells, which had been reprogrammed by defined factors, were designated induced pluripotent stem (iPS) cells. Subsequent, stepwise removal of individual factors from the pool of 24, identified 10 factors which, when removed individually, prevented the formation of G418-resistant colonies. When these 10 genes were introduced in combination into MEFs by retroviral transduction, more ES cell-like colonies were formed than with all 24 factors. Removal of individual factors from the 10-factor pool identified just four genes that when removed resulted in no colonies (KIf4, Oct3/4), greatly reduced colony numbers (Sox2), or colonies containing cells with non-ES cell-like morphology $(c-M y c)$. Thus, the factors encoded by these genes played important roles in inducing pluripotency in MEFs. Combination of these four genes alone resulted in formation of G418-resistant colonies, comparable in number to those formed by the 10 factors. G418-resistant colonies could not be formed by any combination of two factors, while combination of three factors only resulted in colonies, which could not be maintained in culture (minus K/f4 or Oct3/4), or had non-ES cell-like morphology (minus Sox2 or $c-M y c$ ). Thus, it was possible to produce iPS cells by transduction of just four genes- Oct3/4, Sox2, KIf4 and c-Myc. It was initially surprising that Nanog, which in addition to Oct3/4 and Sox2 is a core transcription factor in the maintenance of pluripotency (Boyer et al., 2005), was found not to be required for iPS cell generation. However, more recent studies have clarified the role of Nanog. In mouse ES cells, Nanog suppresses cellular differentiation but is not required for ES cell self-renewal (Chambers et al., 2007).

Using primers, which amplified transcripts of the endogenous genes only, RT-PCR experiments found that iPS cells express most ES cell marker genes. Notably however, endogenous levels of Oct3/4 and Sox2remained relatively low 
in the majority of clones. Using chromatin immunoprecipitation analysis, a number of epigenetic changes, which are associated with gene activation and are characteristic of ES cells, were observed in iPS cells. These changes included increased acetylation of histone $\mathrm{H} 3$, and a decrease in dimethylation of histone 3 lysine 9 (diMeH3K9) at the promoters of Oct3/4 and Nanog. However, $\mathrm{CpG}$ islands in the promoter regions of these genes remained methylated in iPS cells, unlike the same regions in ES cells. DNA microarrays revealed that many of the genes upregulated in iPS cells are expressed specifically in ES cells. However, a number of genes were found to be up-regulated to a greater extent in ES cells than iPS cells, including Dnmt3aand the $L$ IF receptorgene, among others. Taken together, these results showed iPS cells to be similar to ES cells, but not identical.

To determine whether they were functionally pluripotent, iPS cells were injected into immune-deficient mice. Similar to ES cells, many of the iPS clones formed tumours called teratomas, which contain tissues originating from all three germ layers. Histological examination showed that teratomas formed by a number of iPS clones contained differentiated cells from all three germ layers, including neural tissues, cartilage and columnar epithelium. In addition, iPS cells were shown to form embryoid bodies in non-coated plastic dishes. By immunostaining for proteins specific to each germ layer it was found that these embryoid bodies contained differentiated cells originating from each germ layer. Following successful generation of iPS cells from MEFs, tail-tip fibroblasts (TTFs) were isolated from an $\mathrm{Fbx} 15^{\beta \mathrm{geo} / \beta \mathrm{geo}}$ mouse, which expressed green fluorescent protein (GFP), under the control of the constitutive CAG promoter. Following introduction of the four necessary transcription factors, a number of iPS cell colonies were established. When injected into nude mice, these iPS cells again contributed to all three germ layers in teratomas, indicating pluripotency. In addition, iPS clones expressing GFP, were introduced into blastocysts by microinjection. Chimeric mouse embryos, which constitutively expressed GFP in all three germ layers developed from these blastocysts. Thus, the pluripotency of iPS cells was further verified. However, no live chimeras were born, and chimeric embryos were observed only up to day E13.5, further highlighting the fact that Fbx15-selected iPS cells are significantly different from ES cells. Despite the clear differences observed between Fbx15-selected iPS cells and ES cells, the discovery of iPS cells was clearly of great scientific significance. Pluripotency had been induced in somatic cells, and a comprehensive examination of the known functions of each of the four factors was required to understand how they each contribute to the reprogramming process.

\section{The Four Factors: Oct3/4, Sox2, c-Myc and KIf4}

Oct3/4 is a transcription factor known to play a key role in the maintenance and self-renewal of pluripotent cells. It is specifically expressed in pluripotent cells, such as ES cells. ES cells cannot be established from Oct3/4 knockout embryos, while repression of Oct3/4 in ES cells results in differentiation into trophoblast-like cells (Niwa et al., 2000), demonstrating the essential role played by Oct3/4 in the maintenance of pluripotency. Interestingly, Oct3/ 4 is also important in promoting differentiation, as its overexpression by as little as $50 \%$ results in differentiation of ES cells into mesoderm and endoderm (Niwa et al., 2000). Together, these findings suggest that Oct3/4 expression levels require very tight regulation in ES cells. Oct3/4 has been shown to have a large number of target genes, many of which also possess regulatory elements for Sox2 and Nanog (Boyer et al., 2005). Such genes are frequently up-regulated or down-regulated in ES cells, and encode proteins involved in ES cell signalling. Oct3/4 is known to co-operate with Sox2 to regulate a number of genes, including Sox2 and Oct3/4 in a positive feedback loop (Chew et al., 2005) and $\mathrm{Nanog}$ (Kuroda et al., 2005). Binding sites for both Oct3/4 and Sox2 have also been found in a number of other genes specifically expressed in ES cells including Fbx15 (Tokuzawa et al., 2003) and Lefty1 (Nakatake et al., 2006). In addition, two regulatory elements exist, which act as stem-cell-specific enhancers of the Oct3/4 gene. Many regulators are recruited to these elements, and shifts in the balance between positive and negative regulators may give rise to variation in the levels of Oct3/4 expression, in response to external stimuli (Niwa, 2007). Liver receptor homologue 1 (Lrh1) acts as a positive regulatory factor for Oct3/ 4 (Gu et al., 2005), while germ cell nuclear factor (Gcnf) acts as a repressor by recruiting Dnmt3 and promoting methylation of the Oct3/4 promoter (Sato et al., 2006).

Sox2 (SRY-type high mobility group box 2) is a transcription factor, which shares the HMG box DNA binding motif with numerous proteins (Yamanaka, 2007). Like Oct3/4, Sox2 plays an important role in the maintenance of pluripotency in ES cells. Down-regulation of Sox2 in mouse ES cell lines promotes differentiation into trophectoderm as well as other lineages, clearly demonstrating the importance of Sox2 in maintaining pluripotency (Ivanova et al., 2006). As discussed above, genes with Sox2 regulatory elements frequently contain Oct3/4 and Nanog binding sites, and Sox2 acts in combination with Oct3/4 to regulate many genes in ES cells (Boyer et al., 2005). By formation of a heterodimer, Sox2 and Oct3/4 regulate both Sox2 and Oct3/ 4themselves (Chew et al., 2005), as well as Nanog (Kuroda et al., 2005) and Fbx15 (Tokuzawa et al., 2003) among others. In addition, Sox 2 may also act in combination with transcription factors other than Oct3/4 to activate ES-cell associated genes. Rex 1 is an example of such a gene, the transcription of which is regulated by the combined action of Sox2 and Nanog (Shi et al., 2006). Mouse ES cells engineered to overexpress Sox2express markers associated with a wide range of differentiated cell types (Kopp et al., 2008). Therefore it seems that, like for Oct3/4, tight regulation of the level of Sox2 is required for self-renewal of ES cells. Given the essential role played by Sox 2 in the maintenance of pluripotency, the recent discovery that deletion of Sox2 in mouse ES cells can be rescued by the introduction of 0 ct3/4came as a surprise. This seems to suggest that maintenance of Oct3/4 expression may be the major function of Sox2 (Masui et al., 2007).

c-Myc is a basic helix-loop-helix transcription factor with well characterised functions in cell growth, differentiation and proliferation. It is also a proto-oncogene however, and plays a significant role in most human cancers. c-Myc accelerates the cell cycle by activating the transcription of cyclin-E, which promotes the transition from G1 to S-phase (Hooker and Hurlin, 2006). c-Myc is an important downstream target of two separate pathways, each of which are known to support the maintenance of pluripotency in ES cells. These pathways are the LIF (leukaemia inhibitory factor)/STAT3 signalling cascade (Cartwright et al., 2005) and the Wnt signalling cascade (Sato et al., 2004). LIF is required 
for the culture of mouse ES cells, and the signalling cascade induced by LIF results in the activation and translocation to the nucleus of STAT3. Activation of $c-M y c$ transcription is one of the major functions of active STAT3, and further, expression of a stable form of c-Myc promoted ES-cell self-renewal in the absence of LIF. In contrast, over-expression of a dominant negative form of $c-M y c$ promotes differentiation of mouse ES cells (Cartwright et al., 2005). Thus, c-Myc is strongly implicated in the maintenance of pluripotency. The Wnt signalling cascade promotes the self-renewal of both mouse and human ES cells, independently of LIF/STAT3 signalling, and is thought to act by inhibiting GSK3 $\beta$ (Sato et al., 2004). In the absence of LIF, GSK3 $\beta$ phosphorylates c-Myc, which is then targeted for proteasomal degradation. In ES cells, Wnt signalling may inhibit GSK3 $\beta$ and thereby maintain an increased level of c-Myc in ES cells (Cartwright et al., 2005). In addition to its roles in the maintenance of pluripotency, c-Myc possesses further functions, which may also be responsible for its importance in the induction of pluripotency. Firstly, there are as many as 25,000 Myc binding sites in the genome, and c-Myc may bind at numerous sites and recruit histone acetylase complexes (Knoepfler et al., 2006). In addition, by promoting progression from G1 to S phase, it may counteract the anti-proliferative effect of KIf4 (Yamanaka, 2007).

Like c-Myc, the Krüppel-like zinc finger transcription factor KIf4 is targeted by active STAT3. Over-expression of KIf4 inhibits differentiation of ES cells (Li et al., 2005), and it co-operates with both Oct3/4 and Sox2 to activate the proximal promoters of a small number of target genes, including $K / f 4$ itself and Lefty 1 (Nakatake et al., 2006). One interesting characteristic of Klf4 is that it can act both as a tumour-suppressor and an oncogene. It is associated with tumour suppression because it activates p21, which suppresses proliferation. However, Klf4 also down-regulates $p 53$, thereby promoting cell proliferation (Rowland et al., 2005). Thus, in the absence of stable p21, KIf4 switches from a tumour-suppressor to an oncogene. It is also noteworthy that p53 acts as a negative regulator of Nanog, which is a key factor involved in the maintenance of pluripotency (Lin et al., 2005). Thus, by down-regulating $p 53$, Klf4 may indirectly result in the upregulation of Nanog. More recently, KIf4 was shown to be dispensable in the maintenance of the undifferentiated state of mouse ES cells and that Krüppel-like factors (KIfs) are required for self-renewal of ES cells (Jiang et al., 2008). In addition it was demonstrated that Klfs and Nanog share many common target genes and that Klfs regulate Nanog, indicating some integration between KIf and Nanog transcriptional circuitry.

\section{Induction of pluripotency by Four Factors: the model}

Understanding the key functions of each of the four transcription factors has enabled experts in the field to suggest a model of how they act in combination to induce pluripotency (Fig. 2). ES cells are very similar to tumours in that they display a 'transformed' phenotype. This means that they are immortal, proliferate rapidly and form tumours when transplanted into immune-deficient mice (Yamanaka, 2007). Thus, it is not surprising that two tumour-associated factors, c-Myc and Klf4, are required for iPS induction. c-Myc promotes numerous aspects of transformation (Adhikary and Eilers, 2005), and as such, may be responsible for inducing immortality in iPS cells. However, c-Myc also induces p53-dependant apoptosis. A function of KIf4 in the induction of iPS cells may be to down-regulate $p 53$ and counteract this proapoptotic effect of c-Myc (Rowland et al., 2005). As discussed above, however, Klf4 also activates $p 21$ and as a result suppresses cell proliferation. By suppressing $p 21$, another function of c-Myc may be to counteract the anti-proliferative effect of KIf4. Therefore, a delicate balance between the expression levels of cMyc and Klf4 might have to be achieved in order for transformation to occur. Apart from its role in transforming cells, c-Myc may also play a role in loosening chromatin structure. This is important, as pluripotent stem cells are known to have open chromatin structure (Meshorer et al., 2006). c-Myc may modify chromatin by binding at numerous sites, and by recruiting histone acetylase complexes (Knoepfler et al., 2006). By introducing $c-M y c$ and Klf4 alone, tumour cells and not iPS cells may be induced. With an open and accessible chromatin structure, loosened by c-Myc, Oct3/4 and Sox 2 can gain access to their target genes and promote transcription of genes necessary for the induction of pluripotency. As described previously, KIf4 also acts in combination with Oct3/4 and Sox 2 to activate genes. In addition, by down regulating $p 53$, KIf4 allows the up-regulation of Nanog, which together with Oct3/ 4 and Sox2 forms a transcription factor network necessary for maintenance of pluripotency (Boyer et al., 2005). While the underlying mechanism for the production of iPS cells is still not understood fully, current work using doxycycline (dox)-inducible lentiviral vectors has helped to decipher the chronology of pluripotency marker gene expression in mouse iPS cells. Using flow cytometry to analyse the timing of specific marker gene expression, it was shown that alkaline phosphatase was expressed first, followed then by stage-specific embryonic antigen 1 (SSEA1) whereas endogenous Oct4 and Nanog expression was only detected in fully reprogrammed cells (Brambrink et al., 2008). In a similar study, downregulation of surface antigen Thy1 expression was observed before SSEA1 activation during the early phase of reprogramming and activation of endogenous Sox2, Oct4, telomerase and the silenced $\mathrm{X}$ chromosome happened later in the reprogramming process (Stadtfeld et al., 2008a). The ability to identify cells at specific intermediate stages in the reprogramming process (by their specific gene marker expression) should prove useful in further deciphering the molecular basis of this process and improving the methodology for generating iPS cells.

Another important consideration is the cell type used for reprogramming. Mouse iPS cells have been produced from adult liver and stomach cells (Aoi et al., 2008), pancreatic $\beta$ cells (Stadtfeld et al., 2008b) and, using dox-inducible lentiviral vectors, cells from several other somatic tissues (Wernig et al., 2008a). However, reprogramming of mature B lymphocytes requires an additional factor (C/EBP-alpha) or inhibition of Pax5 (Hanna et al., 2008).

\section{Generation of iPS cells of improved quality}

While the discovery of iPS cells by Takahashi and Yamanaka represented a major breakthrough in stem cell research, Fbx15selected iPS cells were only partially reprogrammed. This was evident from the fact that iPS cells differed from ES cells in terms of global gene expression and epigenetic marks. Failure of iPS cells to give rise to live chimeric mice provided further evidence for these differences (Takahashi and Yamanaka, 2006). If iPS cells 
were to ever have a use in regenerative medicine, their quality would have to be improved. In 2007, three groups individually generated improved iPS cells by using either Nanog (Maherali et al., 2007; Okita et al., 2007; Wernig et al., 2007) or Oct3/4 (Wernig et al., 2007) as a selection marker. Both of these factors are more tightly associated with pluripotency than Fbx 15. Drug selection was used by each group to isolate reprogrammed cells, with Yamanaka's group inserting a green fluorescent protein (GFP)-internal ribosome entry site (IRES)-puromycin resistance gene (Puro') cassette into the Nanog locus of ES cells (Okita et al., 2007). Following blastocyst injection, chimeric mouse embryos were obtained that contained the NanogGFP-IRES-Puro' ${ }^{r}$ construct. MEFs were taken from these embryos and transfected with the four known reprogramming factors. The development of puromycin-resistant cell colonies that expressed GFP indicated that these cells expressed the pluripotency gene of interest (Nanog or Oct3/4) and thus, had been reprogrammed (Okita et al., 2007). Each group achieved a significant improvement in the quality of iPS cells. Nanog- and Oct3/4-iPS cells were subjected to rigorous tests, which demonstrated that these iPS cells were almost indistinguishable from ES cells. Following induction of pluripotency, the retroviral transgenes were silenced in Nanog-iPS cells, unlike in Fbx15-iPS cells, possibly due to the action of the de novo methyltransferase, Dnmt3a2 (Okita et al., 2007). Additionally, Nanog-iPS cells expressed most ES cell marker genes including Oct3/4, Sox2 and Nanog from endogenous loci at levels comparable to ES cells. The promoter regions of the Nanogand Oct3/4 genes were fully de-methylated, contrasting with the same regions in Fbx15-iPS cells. In addition, the global patterns of gene expression and DNA methylation were almost identical in NanogiPS cells and ES cells (Maherali et al., 2007; Okita et al., 2007; Wernig et al., 2007). A notable exception was the expression levels of Rex1, which was lower in Nanog-iPS cells than in ES cells (Okita et al., 2007). Histone modification was also highly similar in the improved iPS cells and ES cells, with a bivalent pattern of histone trimethylation, characteristic of ES cells, being observed in Nanog- and Oct3/4-iPS cells (Maherali et al., 2007; Wernig et al., 2007). The observation that silenced X-chromosomes from female somatic cells were re-activated upon generation of Nanog-iPS cells was also important in demonstrating the improved quality of iPS cells using the new selection process. Upon differentiation of Nanog-iPS cells, the X-chromosome was randomly inactivated; further demonstrating the complete reprogramming that had been achieved (Maherali et al., 2007). Nanog- and Oct3/4-iPS cells were also found to be functionally pluripotent. Like Fbx15-iPS cells, they contributed to all three germ layers in both teratomas and embryoid bodies. However, unlike Fbx15-iPS cells, Nanog- and Oct3/4-iPS cells were able to produce live chimeric mice when introduced into blastocysts (Maherali et al., 2007; Okita et al., 2007; Wernig et al., 2007). Significantly, all three groups provided compelling evidence for germ-line competency of iPS cells, with Yamanaka's group successfully raising progeny from Nanog-iPS chimeric mice (Okita et al., 2007).

Further evidence for the complete reprogramming of Oct3/4and Nanog- iPS cells was provided by each of the other two groups. Firstly, Jaenisch and colleagues performed the most rigorous test of pluripotency when they created 'all iPS embryos' by injecting Nanog-iPS cells into tetraploid blastocysts. These blastocysts have the developmental potential to form only placenta, and thus, any resulting embryos consist entirely of donor cells (Wernig et al., 2007). Secondly, Hochedlinger's group used iPS cells to successfully reprogramme somatic cells by cell fusion (Maherali et al., 2007). Taken together, the findings of each of these three groups provided incontrovertible evidence that Nanogand Oct3/4-iPS cells are fully reprogrammed. Interestingly, Jaenisch's group were also able to derive iPS cells using these four factors from normal genetically unmodified somatic donor cells. The iPS cells were isolated based only on their morphology (Meissner et al., 2007). This advance may be key in the application of iPS cell technology for human therapeutics.

Despite these developments, a number of issues remained with the technology before it could be used to generate patientspecific pluripotent stem cells. Firstly, it was unclear why iPS cells were induced with very low efficiency. Less than $1 \%$ of somatic cells expressing the four factors became iPS cells. While the reasons for this are uncertain, a number of possibilities have been suggested (Takahashi and Yamanaka, 2006; Okita et al., 2007). It was suggested that tissue stem cells, which co-exist with fibroblasts in culture, might have been the origin of observed iPS cells. Another possibility is that expression levels of the four 
factors might have to be confined within narrow ranges in order for pluripotency to be induced. Such appropriate expression may occur by chance, only in a small proportion of cells. Alternatively, expression of additional factors may be required to increase the efficiency of iPS cell generation. Secondly, because of the system of retroviral transduction required for induction of iPS cells, tumours developed in a high proportion of chimeric mice, and in mice derived after germline transmission, due to the reactivation of the c-Myc transgene. In order to be useful in a clinical context, it would be necessary to either develop a system of transiently delivering genes, or to remove the necessity for the c-Myc transgene completely.

\section{Safer cell reprogramming}

With the recent discovery that it is possible to generate iPS cells from human somatic cells (Takahashi et al., 2007; Yu et al., 2007; Lowry etal., 2008; Park etal., 2008; Mali etal., 2008), the possibility that iPS cells could be used in patient-specific cell transplantation therapies moved one step closer to becoming a reality. However, the remaining presence of the $c-M y c$ transgene in Yamanaka's protocol remained a barrier to any potential clinical application of iPS cells.

Two very recent studies have demonstrated that it is possible to produce mouse Nanog-iPS cells without the $c-M y c$ transgene (Nakagawa etal., 2008; Wernig etal., 2008b). In these new papers, the remaining three reprogramming genes, namely $0 c t 3 / 4$, Sox2 and $K / f 4$, were retrovirally transduced into MEFs. While it had previously been found that no iPS cell colonies formed in the absence of exogenous $c-M y c$ (Okita et al., 2007), it was reasoned that this may have been due to the timing of drug selection. Thus, cells transfected with three genes only, were cultured for an extended period of time, before drug selection was applied. Both groups found that drug-resistant iPS cell colonies were indeed formed by the three factors devoid of $c-M y c$ if drug selection was delayed sufficiently (Fig. 3). Yamanaka and co-workers found that reprogramming occurred in the absence of $c-M y c$ if selection was delayed until 14 days after transduction (Nakagawa et al., 2008), while Jaenisch and co-workers found that it was necessary to delay drug selection until 30 days after transduction (Wernig et al., 2008b). Despite these differing results, both clearly demonstrated that the rate of reprogramming in the absence of $c-M y c$ is significantly reduced when compared with iPS cells reprogrammed by four factors. Also, fewer iPS cell colonies were formed by three factors than four, while fewer background and non-iPS cell colonies were observed also (Nakagawa et al., 2008). Together, these data suggest that iPS induction in the absence of $c-M y c$ is less efficient but more specific than when $c-M y c$ is present. Nanogselected iPS cells generated without Myc expressed ES-cell marker genes at levels comparable to those in ES cells (Nakagawa et al., 2008), and generated teratomas containing tissues from all three germ layers when injected into nude mice (Wernig et al., 2008b). Importantly, they were also able to generate viable adult chimeric mice, indicating that the iPS cells generated without Myc were of high quality (Nakagawa et al., 2008; Wernig et al., 2008b). Contrasting with chimeras derived from iPS cells generated with Myc, those derived from Myc-iPS cells did not develop tumours within 100 days after birth (Fig. 3) (Nakagawa et al., 2008). This reduced risk of tumour development is an important progression in iPS cell technology. Despite the finding that the $c-M y c$ transgene is dispensable for reprogramming, it remained unclear whether endogenous Myc proteins were involved in iPS generation. Due to the decreased efficiency and delayed timing of reprogramming without $c-M y c$, it was clear that it does play a role. In the future, the discovery of small molecules, which can replace the role of $c-M y c$, would overcome both problems of tumourigenicity and reduced efficiency.

A comprehensive comparative genomic analysis of differentiated cells, stable partially reprogrammed cell lines, fully reprogrammed iPS cells and ES cells was undertaken in an effort to identify the reasons for the low efficiency of iPS cell production (Mikkelsen et al., 2008). ES and iPS cells share similar gene expression patterns and epigenetic states whereas stable, partially reprogrammed cell lines show expression of some differentiationassociated genes and silencing (by DNA hypermethylation) of some pluripotency-associated genes. Interestingly, it was also

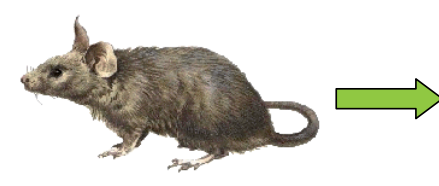

Donor mouse

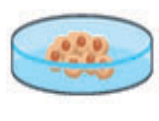

Fibroblast culture
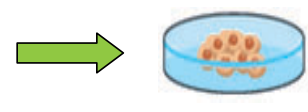

Retroviral addition of the 4 or 3 factors
Drug selection (Delayed when c-Myc is omitted)

\section{Tumours in mice}

\section{No tumours in mice}
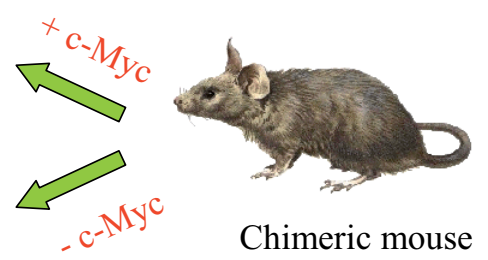

Chimeric mouse
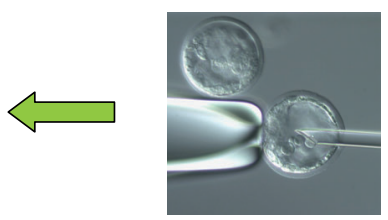

Blastocyst injection

Fig. 3. Induction of induced pluripotent stem (iPS) cells and generation of chimeras. Delaying the drug selection process allows the production of iPS cells without the requirement for c-Myc. Chimeric mice produced by blastocyst injection of these iPS cells show reduced tumour incidence (adapted from Pera and Hasegawa, 2008). 
demonstrated that low success rates in iPS cell generation can be ameliorated by transient RNA inhibition of transcription factors and treatment with DNA methyltransferase inhibitors, thereby suggesting that small molecule treatments can improve the efficiency of iPS cell production and the safety of iPS cells for clinical applications.

Another barrier to the application of iPS cells in human therapeutics is the risk posed by retroviral transduction of the three/four transcription factors. The difficulty of developing safe gene transfer methods is a challenge for both gene and cell therapy approaches. However, the potential of such therapies to treat human disease is so vast as to warrant extensive investigation. To date, the most efficient way to genetically modify cells is to introduce genes by retroviral integration thereby potentially causing insertional mutagenesis, protooncogene activation and tumourigenesis. For an extensive review of current attempts to improve the safety of retroviral integration, see Nienhuis et al., 2006. Encouragingly Yamanaka's group have very recently demonstrated that retroviral integration into specific sites is not required for iPS cell generation (Aoi et al., 2008). At this stage there is no proven safe option to generate iPS cells, without the risks associated with retroviral transfer. The use of RNAi and DNA modification enzyme inhibitors has been demonstrated to improve the efficiency and safety of iPS cell production (Mikkelsen et al., 2008). It is hoped that a better understanding of the gene regulatory circuits and epigenetic modifications involved in cell reprogramming might point to improved small molecule treatments, an approach which is more likely to be applicable in the field of regenerative medicine.

\section{Conclusions}

Since the initial discovery of mouse iPS cells by Takahashi and Yamanaka in 2006, research in this area has advanced at an astonishing rate. In just over a year, the technology used to reprogramme mouse cells has been successfully extended to human cells, while some of the initial problems with mouse iPS cells, including tumourigenicity have been partly addressed. Nevertheless, extensive research is still required with mouse iPS cells before any potential therapeutic use of human iPS cells is realised. The cause of the low efficiency of iPS induction remains to be determined. In addition to gene activation by expression of transcription factors, epigenetic remodelling plays a key role in induction of cellular pluripotency. A greater understanding of this mechanism will be necessary to improve the efficiency of iPS cell generation. Moreover, retroviral transduction involves random integration into the genome and consequently poses a risk of mutagenesis. The future use of alternative gene delivery systems or small molecules, which can replace retroviral gene products, may circumvent this problem. Also, if iPS cells are to be used clinically, methods to direct differentiation and integrate them into tissues are still required. Despite this however, iPS cells represent one of the best hopes for producing patient-specific stem cells for cell-based therapies.

Note added in proof: Promising results demonstrating the therapeutic potential of iPS cells have been reported (Wernig et al., 2008c). Mouse
iPS cells were differentiated into mature, functional neuronal cells and improved the symptoms of a rat model of Parkinson's disease.

\section{Acknowledgements}

We wish to acknowledge funding from Science Foundation Ireland and the National Centre for Biomedical Engineering Science at the National University of Ireland, Galway.

\section{References}

ADHIKARY, S. and EILERS, M. (2005). Transcriptional regulation and transformation by Myc proteins. Nat Rev Mol Cell Bio/6: 635-45.

AOI, T., YAE, K., NAKAGAWA, M., ICHISAKA, T., OKITA, K., TAKAHASHI, K., CHIBA, T. and YAMANAKA, S. (2008). Generation of Pluripotent Stem Cells from Adult Mouse Liver and Stomach Cells. Science 321: 699-702.

BOYER, L. A., LEE, T. I., COLE, M. F., JOHNSTONE, S. E., LEVINE, S. S., ZUCKER, J. P., GUENTHER, M. G., KUMAR, R. M., MURRAY, H. L., JENNER, R. G. et al. (2005). Core transcriptional regulatory circuitry in human embryonic stem cells. Cel/122: 947-56.

BRAMBRINK, T., FOREMAN, R., WELSTEAD, G. G., LENGNER, C. J., WERNIG M., SUH, H. and JAENISCH, R. (2008). Sequential expression of pluripotency markers during direct reprogramming of mouse somatic cells. Cell Stem Cel/2: 151-9.

CARTWRIGHT, P., MCLEAN, C., SHEPPARD, A., RIVETT, D., JONES, K. and DALTON, S. (2005). LIF/STAT3 controls ES cell self-renewal and pluripotency by a Myc-dependent mechanism. Development 132: 885-96.

CHAMBERS, I., SILVA, J., COLBY, D., NICHOLS, J., NIJMEIJER, B., ROBERTSON, M., VRANA, J., JONES, K., GROTEWOLD, L. and SMITH, A. (2007) Nanog safeguards pluripotency and mediates germline development. Nature 450: 1230-1235.

CHEW, J. L., LOH, Y. H., ZHANG, W., CHEN, X., TAM, W. L., YEAP, L. S., LI, P. ANG, Y. S., LIM, B., ROBSON, P. et al. (2005). Reciprocal transcriptional regulation of Pou5f1 and Sox2 via the Oct4/Sox2 complex in embryonic stem cells. $\mathrm{Mol} \mathrm{Cell} \mathrm{BiO} / 25$ : 6031-46.

COWAN, C. A., ATIENZA, J., MELTON, D. A. and EGGAN, K. (2005). Nuclear reprogramming of somatic cells after fusion with human embryonic stem cells. Science 309: 1369-73.

EGLI, D., ROSAINS, J., BIRKHOFF, G. and EGGAN, K. (2007). Developmental reprogramming after chromosome transfer into mitotic mouse zygotes. Nature 447: 679-85

EVANS, M. J. and KAUFMAN, M. H. (1981). Establishment in culture of pluripotential cells from mouse embryos. Nature 292: 154-6.

GU, P., GOODWIN, B., CHUNG, A. C., XU, X., WHEELER, D. A., PRICE, R. R. GALARDI, C., PENG, L., LATOUR, A. M., KOLLER, B. H. et al. (2005). Orphan nuclear receptor $\mathrm{LRH}-1$ is required to maintain Oct4 expression at the epiblast stage of embryonic development. Mol Cell Biol25: 3492-505.

HANNA, J., MARKOULAKI, S., SCHORDERET, P., CAREY, B.W., BEARD, C., WERNIG, M., CREYGHTON, M.P., STEINE, E.J., CASSADY, J.P. et al. (2008). Direct reprogramming of terminally differentiated mature $B$ lymphocytes to pluripotency. Cel/133: 250-64.

HOCHEDLINGER, K. and JAENISCH, R. (2006). Nuclear reprogramming and pluripotency. Nature 441: 1061-7.

HOOKER, C. W. and HURLIN, P. J. (2006). Of Myc and Mnt. J Cel/ Sci119: 20816.

IVANOVA, N., DOBRIN, R., LU, R., KOTENKO, I., LEVORSE, J., DECOSTE, C., SCHAFER, X., LUN, Y. and LEMISCHKA, I. R. (2006). Dissecting self-renewal in stem cells with RNA interference. Nature 442: 533-8.

JIANG, J., CHAN, Y.S., LOH, Y.H., CAI, J., TONG, G.Q., LIM, C.A., ROBSON, P., ZHONG, S. and NG, H.H. (2008) A core Klf circuitry regulates self-renewal of embryonic stem cells. Nat Cel/ Bio/10: 353-360.

KNOEPFLER, P. S., ZHANG, X. Y., CHENG, P. F., GAFKEN, P. R., MCMAHON S. B. and EISENMAN, R. N. (2006). Myc influences global chromatin structure. Embo J25: 2723-34.

KOPP, J.L., ORMSBEE, B.D., DESLER, M. and RIZZINO, A. (2008) Small increases in the level of Sox 2 trigger the differentiation of mouse embryonic stem 
cells. Stem Cells 26: 903-911.

KURODA, T., TADA, M., KUBOTA, H., KIMURA, H., HATANO, S. Y., SUEMORI, H., NAKATSUJI, N. and TADA, T. (2005). Octamer and Sox elements are required for transcriptional cis regulation of Nanog gene expression. $\mathrm{Mol} \mathrm{Cel}$ Bio/25: 2475-85.

LI, Y., MCCLINTICK, J., ZHONG, L., EDENBERG, H. J., YODER, M. C. and CHAN, R. J. (2005). Murine embryonic stem cell differentiation is promoted by SOCS3 and inhibited by the zinc finger transcription factor Klf4. Blood 105: 635-7.

LIN, T., CHAO, C., SAITO, S., MAZUR, S. J., MURPHY, M. E., APPELLA, E. and $X U, Y$. (2005). p53 induces differentiation of mouse embryonic stem cells by suppressing Nanog expression. Nat Cell Bio/7: 165-71.

LOWRY, W. E., RICHTER, L., YACHECHKO, R., PYLE, A. D., TCHIEU, J., SRIDHARAN, R., CLARK, A. T. and PLATH, K. (2008). Generation of human induced pluripotent stem cells from dermal fibroblasts. Proc Nat/ Acad Sci USA 105: 2883-8.

MAHERALI, N., SRIDHARAN, R., XIE, W., UTIKAL, J., EMINLI, S., ARNOLD, K., STADTFELD, M., YACHECHKO, R., TCHIEU, J., JAENISCH, R. et al. (2007). Directly reprogrammed fibroblasts show global epigenetic remodeling and widespread tissue contribution. Cell Stem Cel/1: 55-70.

MALI, P., YE, Z., HOMMOND H. H., YU, X., LIN, J., CHEN, G., ZOU, J. and CHENG, L. (2008). Improved efficiency and pace of generating induced pluripotent stem cells from human adult and fetal fibroblasts. Stem Cel/s 26: 1998-2005.

MARTIN, G. R. (1981). Isolation of a pluripotent cell line from early mouse embryos cultured in medium conditioned by teratocarcinoma stem cells. Proc Nat/ Acad SCi USA 78: 7634-8.

MASUI, S., NAKATAKE, Y., TOYOOKA, Y., SHIMOSATO, D., YAGI, R., TAKAHASHI, K., OKOCHI, H., OKUDA, A., MATOBA, R., SHAROV, A. A. et al. (2007). Pluripotency governed by Sox2 via regulation of Oct3/4 expression in mouse embryonic stem cells. Nat Cel/ Bio/9: 625-35.

MEISSNER, A., WERNIG, M. and JAENISCH, R. (2007). Direct reprogramming of genetically unmodified fibroblasts into pluripotent stem cells. Nat Biotechno/25: 1177-81.

MESHORER, E., YELLAJOSHULA, D., GEORGE, E., SCAMBLER, P. J., BROWN, D. T. and MISTELI, T. (2006). Hyperdynamic plasticity of chromatin proteins in pluripotent embryonic stem cells. Dev Cel/ 10: 105-16.

MIKKELSEN, T.S., HANNA, J., ZHANG, X., KU, M., WERNIG, M., SCHORDERET, P., BERNSTEIN, B.E., JAENISCH, R., LANDER, E.S. and MEISSNER, A. (2008) Dissecting direct reprogramming through integrative genomic analysis. Nature 454: 49-55.

NAKAGAWA, M., KOYANAGI, M., TANABE, K., TAKAHASHI, K., ICHISAKA, T., AOI, T., OKITA, K., MOCHIDUKI, Y., TAKIZAWA, N. and YAMANAKA, S. (2008). Generation of induced pluripotent stem cells without Myc from mouse and human fibroblasts. Nat Biotechno/26: 101-6.

NAKATAKE, Y., FUKUI, N., IWAMATSU, Y., MASUI, S., TAKAHASHI, K., YAGI, R., YAGI, K., MIYAZAKI, J., MATOBA, R., KO, M. S. et al. (2006). KIf4 cooperates with Oct3/4 and Sox2 to activate the Lefty1 core promoter in embryonic stem cells. Mol Cell Bio/26: 7772-82.

NIENHUIS, A. W., DUNBAR, C. E. and SORRENTINO, B. P. (2006). Genotoxicity of retroviral integration in hematopoietic cells. Mol Ther 13: 1031-49.

NIWA, H., MIYAZAKI, J. and SMITH, A. G. (2000). Quantitative expression of Oct$3 / 4$ defines differentiation, dedifferentiation or self-renewal of ES cells. Nat Genet 24: 372-6.

NIWA, H. (2007). How is pluripotency determined and maintained? Development 134: 635-46.

OKITA, K., ICHISAKA, T. and YAMANAKA, S. (2007). Generation of germlinecompetent induced pluripotent stem cells. Nature 448: 313-7.

PARK, I. H., ZHAO, R., WEST, J. A., YABUUCHI, A., HUO, H., INCE, T. A., LEROU, P. H., LENSCH, M. W. and DALEY, G. Q. (2008). Reprogramming of human somatic cells to pluripotency with defined factors. Nature 451: 141-6.

PERA, M.F. and HASEGAWA, K. (2008) Simpler and safer cell reprogramming. Nat Biotech 26: 59-60.

ROWLAND, B. D., BERNARDS, R. and PEEPER, D. S. (2005). The KLF4 tumour suppressor is a transcriptional repressor of p53 that acts as a context-depen- dent oncogene. Nat Cel/ BiO/7: 1074-82.

SATO, N., MEIJER, L., SKALTSOUNIS, L., GREENGARD, P. and BRIVANLOU, A $H$. (2004). Maintenance of pluripotency in human and mouse embryonic stem cells through activation of Wnt signaling by a pharmacological GSK-3-specific inhibitor. Nat Med 10: 55-63.

SATO, N., KONDO, M. and ARAI, K. (2006). The orphan nuclear receptor GCNF recruits DNA methyltransferase for Oct-3/4 silencing. Biochem Biophys Res Commun 344: 845-51.

SHI, W., WANG, H., PAN, G., GENG, Y., GUO, Y. and PEI, D. (2006). Regulation of the pluripotency marker Rex-1 by Nanog and Sox2. J Biol Chem 281: 2331925.

STADTFELD, M., MAHERALI, N., BREAULT, D. T. and HOCHEDLINGER, K. (2008a). Defining molecular cornerstones during fibroblast to iPS cell reprogramming in mouse. Cel/ Stem Cel/2: 230-40.

STADTFELD, M., BRENNAND, K. and HOCHEDLINGER, K. (2008b). Reprogramming of pancreatic Beta cells into induced pluripotent stem cells. Curr Bio/18: 890-4.

SURANI, M. A., HAYASHI, K. and HAJKOVA, P. (2007). Genetic and epigenetic regulators of pluripotency. Cel/128: 747-62.

TADA, M., TAKAHAMA, Y., ABE, K., NAKATSUJI, N. and TADA, T. (2001). Nuclear reprogramming of somatic cells by in vitro hybridization with ES cells. Curr Biol 11: $1553-8$.

TAKAHASHI, K. and YAMANAKA, S. (2006). Induction of pluripotent stem cells from mouse embryonic and adult fibroblast cultures by defined factors. Cel/126: 663-76.

TAKAHASHI, K., TANABE, K., OHNUKI, M., NARITA, M., ICHISAKA, T., TOMODA, $\mathrm{K}$. and YAMANAKA, S. (2007). Induction of pluripotent stem cells from adult human fibroblasts by defined factors. Cel/131: 861-72.

THOMSON, J. A., ITSKOVITZ-ELDOR, J., SHAPIRO, S. S., WAKNITZ, M. A., SWIERGIEL, J. J., MARSHALL, V. S. and JONES, J. M. (1998). Embryonic stem cell lines derived from human blastocysts. Science 282: 1145-7.

TOKUZAWA, Y., KAIHO, E., MARUYAMA, M., TAKAHASHI, K, MITSUI, K., MAEDA, M., NIWA, H. and YAMANAKA, S. (2003). Fbx15 is a novel target of Oct $3 / 4$ but is dispensable for embryonic stem cell self-renewal and mouse development. $\mathrm{Mo} / \mathrm{Ce} / \mathrm{BiO} / 23:$ 2699-708.

WERNIG, M., MEISSNER, A., FOREMAN, R., BRAMBRINK, T., KU, M., HOCHEDLINGER, K., BERNSTEIN, B. E. and JAENISCH, R. (2007). In vitro reprogramming of fibroblasts into a pluripotent ES-cell-like state. Nature 448: 318-24.

WERNIG, M., LENGNER, C.J., HANNA, J., LODATO, M.A., STEINE, E., FOREMAN, R., STAERK, J., MARKOULAKI, S. and JAENISCH, R. (2008a). A druginducible transgenic system for direct reprogramming of multiple somatic cell types. Nat Biotechnol. 26:916-924.

WERNIG, M., MEISSNER, A., CASSADY, J. P. and JAENISCH, R. (2008b). c-Myc is dispensable for direct reprogramming of mouse fibroblasts. Cel/ Stem Cel/2: 10-2.

WERNIG, M., ZHAO, J.P., PRUSZAK, J., HEDLUND, E., FU, D., SOLDNER, F. BROCCOLI, V., CONSTANTINE-PATON, M., ISACSON, O and JAENISCH, R. (2008c). Neurons derived from reprogrammed fibroblasts functionally integrate into the fetal brain and improve symptoms of rats with Parkinson's disease. Proc Natl Acad Sci USA 105: 5856-61.

WILMUT, I., SCHNIEKE, A. E., MCWHIR, J., KIND, A. J. and CAMPBELL, K. H. (1997). Viable offspring derived from fetal and adult mammalian cells. Nature 385: 810-3.

YAMANAKA, S. (2007). Strategies and new developments in the generation of patient-specific pluripotent stem cells. Cell Stem Cel/1: 39-49.

YANG, X., SMITH, S. L., TIAN, X. C., LEWIN, H. A., RENARD, J. P. and WAKAYAMA, T. (2007). Nuclear reprogramming of cloned embryos and its implications for therapeutic cloning. Nat Genet 39: 295-302.

YU, J., VODYANIK, M. A., SMUGA-OTTO, K., ANTOSIEWICZ-BOURGET, J., FRANE, J. L., TIAN, S., NIE, J., JONSDOTTIR, G. A., RUOTTI, V., STEWART, R. et al. (2007). Induced pluripotent stem cell lines derived from human somatic cells. Science 318: 1917-20. 


\section{Further Related Reading, from previously published Int. J. Dev. Biol. articles}

See our recent Special Issue Fertilization, in honor of David L. Garbers and edited by Paul M. Wassarman and Victor D. Vacquier at: http://www.ijdb.ehu.es/web/contents.php?vol=52\&issue=5-6

See our recent Special Issue Ear Development edited by Fernando Giraldez and Bernd Fritzsch at: http://www.ijdb.ehu.es/web/contents.php?vol=51\&issue=6-7

Comparative study of mouse and human feeder cells for human embryonic stem cells Livia Eiselleova, Iveta Peterkova, Jakub Neradil, Iva Slaninova, Ales Hamp and Petr Dvorak Int. J. Dev. Biol. (2008) 52: 353-363

Spa-1 regulates the maintenance and differentiation of human embryonic stem cells Young-Jin Lee, Hee-Young Nah, Seok-Ho Hong, Ji-Won Lee, Ilkyung Jeon, Jhang Ho Pak, Joo-Ryung Huh, Sung-Hoon Kim, HeeDong Chae, Byung-Moon Kang, Chul Geun Kim and Chung-Hoon Kim

Int. J. Dev. Biol. (2008) 52: 43-53

Retinal stem cells in vertebrates: parallels and divergences

Marcos A. Amato, Emilie Arnault and Muriel Perron

Int. J. Dev. Biol. (2004) 48: 993-1001

Derivation of keratinocyte progenitor cells and skin formation from embryonic stem cells.

Daniel Aberdam

Int. J. Dev. Biol. (2004) 48: 203-206

Transdifferentiation of corneal epithelium: evidence for a linkage between the segregation of epidermal stem cells and the induction of hair follicles during embryogenesis.

David J Pearton, Corinne Ferraris and Danielle Dhouailly

Int. J. Dev. Biol. (2004) 48: 197-201

A P19Cl6 GFP reporter line to quantify cardiomyocyte differentiation of stem cells.

Jennifer C Moore, Rene Spijker, Anton C Martens, Teun de Boer, Martin B Rook, Marcel A G van der Heyden, Leon G Tertoolen and Christine L Mummery

Int. J. Dev. Biol. (2004) 48: 47-55

Embryonic stem cell differentiation and the analysis of mammalian development. Stephen J Rodda, Steven J Kavanagh, Joy Rathjen and Peter D Rathjen Int. J. Dev. Biol. (2002) 46: 449-458

From hematopoietic stem cells to neural stem cells S Bonilla, P Alarcon, R Villaverde, P Aparicio, A Silva, S Martinez Int. J. Dev. Biol. (2001) 45: S67-S68

The generation and in vivo differentiation of murine embryonal stem cells genetically null for either $\mathrm{N}$-cadherin or $\mathrm{N}$ - and $\mathrm{P}$-cadherin.

R Moore, G L Radice, M Dominis and R Kemler

Int. J. Dev. Biol. (1999) 43: 831-834

The germ cell-the mother of all stem cells.

P J Donovan

Int. J. Dev. Biol. (1998) 42: 1043-1050

The avian neural crest as a model system for the study of cell lineages. J Smith

Int. J. Dev. Biol. (1990) 34: 157-162

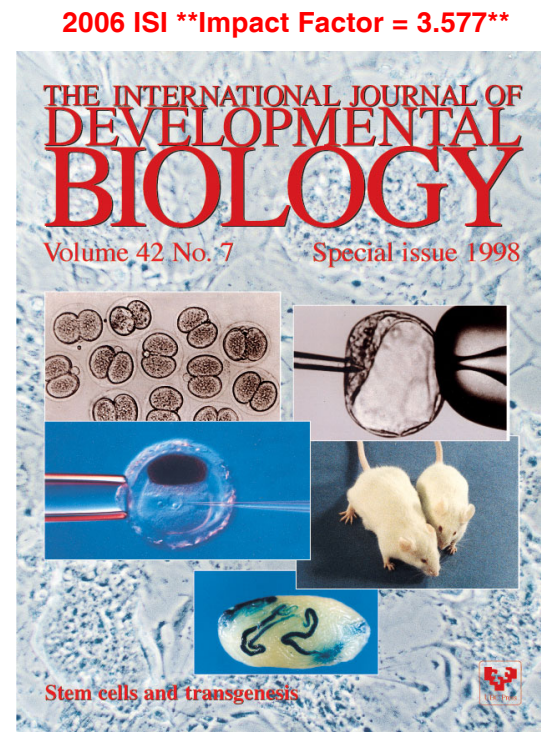

